\title{
Effectiveness of progressive muscle relaxation therapy as a worksite health promotion program in the automobile assembly line
}

\author{
Bala Murali SUNDRAM ${ }^{1 *}$, Maznah DAHLUI ${ }^{1}$ and Karuthan CHINNA ${ }^{1}$ \\ ${ }^{1}$ Department of Social and Preventive Medicine, Faculty of Medicine Building, University of Malaya, Malaysia \\ Received April 26, 2014 and accepted November 9, 2015 \\ Published online in J-STAGE December 26, 2015
}

\begin{abstract}
The aim of this study was to examine the effectiveness of Progressive Muscle Relaxation (PMR) as part of a Worksite Health Promotion Program on self-perceived stress, anxiety and depression among male automotive assembly-line workers through a quasi-experimental trial. Two assembly plants were chosen with one receiving PMR therapy and the other Pamphlets. Intentionto-treat analysis was conducted to test the effectiveness of the relaxation therapy. Stress, Depression and Anxiety levels were measured using the shortened DASS-21 questionnaire. Data were analyzed using Chi-square, Independent sample t test and Repeated-measures analysis of variance to test the significance of the effects of intervention (time * group) for the measures of Stress, Depression and Anxiety. Significant favourable intervention effects on stress were found in the PMR group (Effect size $=0.6$ ) as compared to the Pamphlet group (Effect size $=0.2$ ). There was a significant group *time interaction effect $(p<0.001)$ on Stress levels. Depression and Anxiety levels were minimal at baseline in both the groups with mild or no reduction in levels. The improvement in stress levels showed the potential of PMR therapy as a coping strategy at the workplace. Further research in this field is necessary to examine the beneficial effects of coping strategies in the workplace.
\end{abstract}

Key words: Psychosocial stress, Occupational health and safety management system, Occupational epidemiology, Risk management, Workload

\section{Introduction}

Stress is a major public health concern as of recent decade. An imbalance between excessive demands and a person's ability to cope with them, ultimately leads to stress. Stress has harmful consequences on the physical, psychosocial and mental health thus causing deleterious effect on the individual, organisation and the society ${ }^{1,2)}$.

Automotive assembly line work is often performed in a workplace environment with physical hazards like noise, vibrations and dangerous machines which can be important

*To whom correspondence should be addressed.

E-mail: balamurali@siswa.um.edu.my

C2016 National Institute of Occupational Safety and Health stress factors ${ }^{3-5)}$. The feeling that supervisors do not care about creating a good work environment is another important factor of stress $^{6-10)}$. Furthermore, technical development in assembly line work, especially in large companies, has often resulted in more complicated tasks for the workers who may have difficulty in over-viewing all the steps in production. This can easily build up a fear of uncertainty and naturally more stress.

Considering these issues, implementation of stress management training in the form of a Worksite Health Promotion Program (WHPP) has become pertinent. Several WHPP to curb job strain have been developed over the years to counter occupational stress, anxiety and depression. The number of studies on worksite stress intervention for the past decade has been gradually increasing and evi- 
dence for its effectiveness has been accumulating ${ }^{11}$. Stress management training provides a psychological education program for individual employees to teach and empower themselves, hence becoming aware and develop effective skills to cope with stress ${ }^{12,13)}$. The development of stress management programs at workplaces are still rather limited $^{14)}$

Evidence suggests that stress relaxation techniques are one of the most effective training programs to enhance psychological resources and reduce psychological distress $^{15,16)}$. Majority of stress relaxation techniques are considered safe in healthy adults and there have been no severe adverse effects reported ${ }^{17)}$. Hence, health education in the form of individual-focused Progressive Muscle Relaxation (PMR) therapy is essential in coping with stress.

PMR is an effective and widely used strategy for stress relief that creates a state of deep relaxation by involving alternate tensing and relaxing of muscles ${ }^{18)}$. It was developed by Edmund Jacobson ${ }^{19,20)}$ based on the theory of psycho-biological state called neuromuscular hypertension as the basis for a variety of negative emotional states and psychosomatic diseases $^{21)}$.

The objective of this study was to assess the impact of PMR as part of a WHPP on the level of stress, depression and anxiety among automotive assembly line workers. We hypothesized that stress, depression and anxiety scores of the PMR group will be significantly reduced as to the comparison group's scores after applying the relaxation therapy.

\section{Materials and Methods}

\section{Study design}

A quasi-experimental study was conducted in two automotive assembly plants in a district in Malaysia over a period of 9 months from January 2012 to September 2012. The study population were automotive assembly line workers directly attached to the Body shop, Paint shop and Assembly section of the plant. Plant A was selected as the PMR group and Plant B the pamphlet group.

Inclusion criteria were all male workers directly attached to the production line and who had been working at the site for more than 1 year. Respondents with psychiatric illnesses with or without medication, having prior training or current use of relaxation therapy, working less than 1 year and respondents without consent were excluded.

An intensive effort was made to ensure that all employees at both automotive plants were made aware of this intervention, with details of the intervention kept strictly confidential. This effort included advertising the interven- tion at the in-house clinic and canteen, placing posters prominently in the clinic, handing out fliers in employee cafeterias during lunchtime and asking employees who had already participated to make their co-workers aware of this investigation.

\section{Sample size estimation}

Sample size was estimated using the Power and Sample size calculator ${ }^{22,23)}$ for continuous outcomes and two sample means with power of $80 \%$ and alpha of $5 \%$. Sample size calculation was based on the mean outcome in control and experimental group as well as standard deviation of outcome for stress levels in a recent quasi-experimental on the impact of applied progressive deep muscle relaxation training on the level of depression, anxiety and stress among prostate cancer patients ${ }^{24)}$. The calculated sample size was 147 in each group and total sample size required was 294 assembly workers. After considering an attrition rate of $20 \%$, the calculated sample size in each group was 176 and total sample size was 352 assembly workers. Confidence interval was set at $95 \%$ and statistical significance declared at two-tailed $p$ value $<0.05$.

The hypothesis tested in this study is as follows:

H10: Automotive assembly line workers do not report a decrease in stress, depression and anxiety levels as a result of participating in PMR therapy to a significant extent compared to automotive assembly line workers who do not participate.

H1A: Automotive assembly line workers report a decrease in stress, depression and anxiety levels as a result of participating in PMR therapy to a significant extent compared to automotive assembly line workers who do not participate.

\section{Study procedure}

Recruitment process in both the plants was undertaken within the assembly line in which an "Anti-Stress Wellness Clinic" was set up next to the already existing in-house clinic in both plants. The clinic was opened daily from Monday to Saturday, according to the hours stipulated by the management. Recruitment was targeted during their breaks to avoid any disruption to the work process at the company.

The intervention in Plant A was PMR therapy as part of a WHPP. Respondents from Plant A were taught and given a training session on the components of PMR techniques by the primary investigator who had himself undergone training with a certified trainer in relaxation techniques in the Department of Psychiatry and Rehabilitation Medicine, 
University Malaya Medical Centre. The respondents were briefed on stress and its ill effects followed by a 15 minute PMR training session.

During the relaxation session, the respondents were seated in a quiet room and were instructed to follow the PMR exercises demonstrated by the investigator. It involved a two-step process derived from Jacobsen's original PMR (Jacobson, 1938) in which the respondents systematically tense for five seconds and relax for ten seconds different muscle groups in the body, starting with the feet, legs, hips, stomach, chest, back, shoulders, arms, hands, neck and face ${ }^{17)}$.

The respondents were advised to practice the relaxation exercise at home. They were encouraged to keep a record, on their home-based relaxation practices in a minilog booklet supplied by the researcher. To supplement the training session, the respondents were given graphical leaflets on PMR techniques in which they could use as a guide while practicing at home. The investigator initiated phone calls, short messaging services (SMS's) and emails to encourage and monitor the respondent's compliance.

Baseline assessment was done using the shortened Depression, Anxiety Stress Scale-21 (DASS-21) selfadministered questionnaire to collect information on socio-demographic characteristics and level of stress. DASS-21 was used at baseline in January 2012 and end of each reinforcement sessions, $3^{\text {rd }}$ month (March 2012), $5^{\text {th }}$ month (May 2012), $7^{\text {th }}$ month (July 2012) and $9^{\text {th }}$ month (September 2012) to assess the stress levels. The four follow-up reinforcement sessions from baseline were conducted to promote compliance and to address issues in relation to the relaxation therapy.

The comparison group in Plant B was not given any relaxation therapy. They were only given pamphlets on stress and its ill-effects and only minimal general information on how to reduce stress in their daily life. Only two levels of stress assessments were done, at baseline and end of $9^{\text {th }}$ month with DASS-21, as it did not require any formal training.

\section{Research assessment}

Self-administered DASS-21 is the short-form of Lovibond and Lovibond's 42-item self-report which measures the negative emotional states of depression, anxiety and stress $^{25)}$. The questionnaire consists of three scales: DASSDepression Scale (Cronbach's alpha=0.81), DASS-Anxiety Scale (Cronbach's alpha $=0.85)$ and DASS-Stress Scale $(\text { Cronbach's alpha }=0.85)^{25,26}$. There are seven items for depression (DASS-Depression), seven items for anxiety
(DASS-Anxiety) and seven items for stress (DASS-Stress). The Depression scale assesses the dysphoria, hopelessness, devaluation of life, self-depreciation, adhedonia, inertia and lack of interest. The Anxiety scale assesses the autonomic arousal, skeletal muscle effects, situational anxiety and subjective experience of anxious affects and the Stress scale assesses the difficulty in relaxing, nervous arousal and being easily upset or agitates, irritable or over-react and impatient ${ }^{27}$. The DASS assessment has been translated into various languages ${ }^{28-30)}$. The translated Malay version of DASS-21 demonstrated good concurrent and criterionrelated validity with a Cronbach's alpha of $0.79^{31)}$.

In this study the Malay version of DASS-21 was used. Respondents were informed to use a 4 point Likert scale $(0=$ Did not apply to me at all, $1=$ Applied to me to some degree, or some of the time, $2=$ Applied to me a considerable degree, or a good part of the time, and $3=$ Applied to me very much, or most of the time) to rate the extent to which they have experienced over the past 9 months. The respective scores for Stress, Depression and Anxiety subscale were calculated by summing the scores and multiplying by two to get the final score. The levels of severity ratings for Stress subscale are Normal $(0-14)$, Mild (15-18), Moderate (19-25), Severe (26-33) and Very Severe $(34+)$; whereas for Anxiety subscale are Normal $(0-7)$, Mild (8-9), Moderate (10-14), Severe (15-19) and Very Severe $(20+)$ and finally for Depression subscale are Normal (0-9), Mild (10-13), Moderate (14-20), Severe $(21-27)$ and Very Severe $(28+)$. The higher scores indicated greater stress, anxiety and depression level ${ }^{25}$.

\section{Statistical analysis}

Data entry and analysis was done using the SPSS version 12.0.1 (SPSS Inc., Chicago, Illinois, USA). Descriptive statistics was computed in relation to the description of the sample (age group, marital status, level of education, salary obtained and assembly line units/sections), as well as means and standard deviations for the baseline and $9^{\text {th }}$ month scores of DASS-21 questionnaire. Baseline demographic and stress levels of Plant A and Plant B were analysed using Chi-square and t-testing.

An Independent Sample Test (including mean, standard deviation, standard error mean, and Levene's Test for Equality of Variances) was performed, as well as a t-test that gave $t$ values, degrees of freedom (df), significance (two-tailed), mean difference, standard error (SE) difference and upper and lower level for $95 \%$ confidence interval of the standard error difference. The effect size (Cohen's d) was calculated as a standardized measure of change ${ }^{32)}$. 


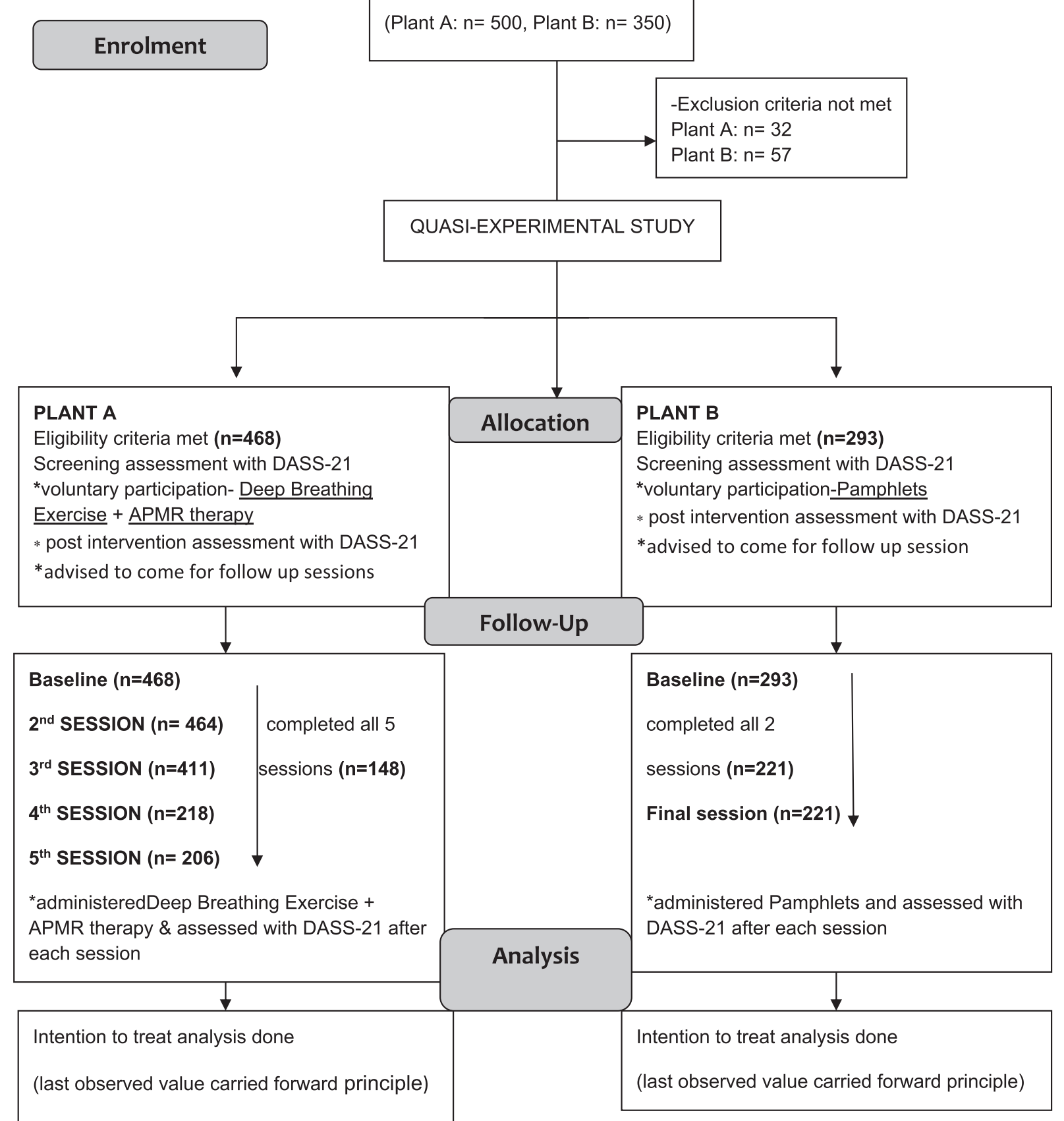

Fig. 1. CONSORT Flow Chart of Study

Inferential analysis was performed to address the research questions of this study using two-tailed tests and an alpha level of .05 . Intention to treat analysis was performed to provide unbiased assessments of treatment efficacy and to ascertain the effects of intervention. Missing values among the participants lost to follow up were replaced with baseline score values. This principle was according to the last observation carried forward principle. Per protocol analysis was also conducted to allow the new treatment to show additional efficacy as it closely reflects the scientific model underlined in the protocol.

Repeated-measures analysis of variance (RMANOVA) was used to test the significance of the effects of intervention (time ${ }^{*}$ group) for the measures of Stress, Depres- 
sion and Anxiety. It was used in the analysis to compare the mean response over time between trial and comparison groups. The rationale for the RMANOVA is to regard time as a factor addition to treatment. A CONSORT checklist was used to improve the quality of the research ${ }^{33)}$ as in Fig. 1 .

\section{Results}

A total of 468 respondents in Plant A and 293 in Plant B met inclusion criteria and participated in the study. At the end of study, there were 148 respondents in Plant A and 221 respondents in Plant B. The socio-demographic characteristics are shown in Table 1. Both groups are homogenous at baseline $(p>0.05)$. Table 2 shows the homogeneity of the demographic characteristics of the participants who took part in the study as well as non-participants at the end of study in both groups.

Analysis was first conducted on Intention-to-Treat (ITT) basis, than replicated Per-protocol, after removal of noncompleters, i.e., the participants who attended fewer than 5 sessions. Per-protocol analysis was conducted for 148 completers from Group A and 221 completers from Group B, who participated in all 5 sessions. In the per-protocol analysis, favourable interventional effects on stress levels were observed, more in Group A ( $\mathrm{F}=256.246, \mathrm{df}=1, p<0.001$, Effect size $=0.6)$ than compared to Group B $(\mathrm{F}=66.072$, $\mathrm{df}=1, p<0.001$, Effect size $=0.2$ ). Reduction in depression and anxiety levels in both the groups were however not significant with a very small effect size $(<0.2)$.

\section{Outcomes of DASS-21 Stress subscale}

Table 3 shows the change in mean scores of DASS21 Stress subscale for Group A and B from baseline to $9^{\text {th }}$ month (within group). Significant changes occurred in Group A (moderate effect size) as compared to Group B (small effect size) across time. Table 3 also shows the difference in mean score of DASS-21 Stress subscale, between the groups at baseline and $9^{\text {th }}$ month. The independent sample $\mathrm{t}$ test indicated no difference $(p>0.05)$ in baseline scores for Group A $($ Mean $=34.57, \mathrm{SD}=3.74)$ and Group B $($ Mean=34.83, SD=2.40), but however there were significant differences $(p<0.001)$ at $9^{\text {th }}$ month between Group A (Mean=26.10, SD=6.64) and Group B (Mean $=32.62, \mathrm{SD}=4.83$ ).

Table 4 shows there was a significant main effect for group assignment $[\mathrm{F}(1,759)=270.27, p<0.001]$, indicating that both groups differed in their average DASS-21 Stress subscale scores across time. There was a significant main effect for time $[F(1,759)=48,335.71, p<0.001]$, indicat-

Table 1. Socio-demographic characteristics of Group A $(n=468)$ \& Group B $(n=293)$ at baseline

\begin{tabular}{lcccc}
\hline \multirow{2}{*}{$\begin{array}{c}\text { Socio-demographic } \\
\text { characteristics }\end{array}$} & Group A (n=468) & Group B (n=293) & & \\
\cline { 2 - 3 } Age (year) & Mean (\%) & Mean (\%) & & $p$-value \\
$20-25$ & $255(54.5)$ & $170(58.0)$ & $1.415(3)$ & 0.702 \\
$26-30$ & $170(36.3)$ & $102(34.8)$ & & \\
$31-40$ & $32(6.8)$ & $16(5.5)$ & & \\
$>40$ & $11(2.4)$ & $5(1.7)$ & & \\
Marital status & & & & \\
Single & $243(51.9)$ & $149(50.9)$ & $0.083(1)$ & 0.774 \\
Married & $225(48.1)$ & $144(49.1)$ & & \\
Level of education & & & & \\
Certificate & $249(53.2)$ & $148(50.5)$ & $0.524(1)$ & 0.469 \\
Diploma & $219(46.8)$ & $145(49.5)$ & & \\
Basic salary (RM) & & & & \\
$1000-2000$ & $380(81.2)$ & $245(83.6)$ & $1.786(2)$ & 0.409 \\
2001-3000 & $80(17.1)$ & $46(15.7)$ & & \\
$>3000$ & $8(1.7)$ & $2(0.7)$ & & \\
Assembly Unit & & & & \\
Paint shop & $139(29.7)$ & $92(31.4)$ & $0.795(2)$ & 0.672 \\
Body shop & $179(38.2)$ & $116(39.6)$ & & \\
Assembly shop & $150(32.1)$ & $85(29.0)$ & & \\
\hline
\end{tabular}


Table 2. Socio-demographic characteristics of Plant A \& Plant B at $9^{\text {th }}$ month

\begin{tabular}{|c|c|c|c|c|c|c|c|c|}
\hline \multirow[b]{2}{*}{$\begin{array}{l}\text { Socio-demographic } \\
\text { characteristics }\end{array}$} & \multicolumn{4}{|c|}{ Completers (369) } & \multicolumn{4}{|c|}{ Non completers (392) } \\
\hline & $\begin{array}{c}\text { Group } \\
\text { A (148) } \\
\text { Mean (\%) }\end{array}$ & $\begin{array}{c}\text { Group } \\
\text { B (221) } \\
\text { Mean (\%) }\end{array}$ & $\begin{array}{l}X^{2} \\
(\mathrm{df})\end{array}$ & $\begin{array}{c}p \\
\text { value }\end{array}$ & $\begin{array}{c}\text { Group } \\
\text { A }(320) \\
\text { Mean }(\%)\end{array}$ & $\begin{array}{c}\text { Group } \\
\text { B (72) } \\
\text { Mean (\%) }\end{array}$ & $\begin{array}{l}X^{2} \\
(\mathrm{df})\end{array}$ & $\begin{array}{c}p \\
\text { value }\end{array}$ \\
\hline \multicolumn{9}{|l|}{ Age (year) } \\
\hline $20-25$ & $79(53.4)$ & $129(58.4)$ & & & $176(55.0)$ & $41(56.9)$ & & \\
\hline $26-30$ & $54(36.5)$ & $78(35.3)$ & 2.169 & 0.538 & $115(35.9)$ & $24(33.3)$ & 0.392 & 0.942 \\
\hline $31-40$ & $11(7.4)$ & $11(5.0)$ & (3) & & $23(7.2)$ & $5(6.9)$ & (3) & \\
\hline$>40$ & $4(2.7)$ & $3(1.4)$ & & & $6(1.9)$ & $2(2.8)$ & & \\
\hline \multicolumn{9}{|l|}{ Marital status } \\
\hline Single & $74(50)$ & $108(48.9)$ & 0.045 & 0.831 & $164(51.2)$ & $41(56.9)$ & 0.764 & 0.382 \\
\hline Married & $74(50)$ & $113(51.1)$ & $(1)$ & & $156(48.8)$ & $31(43.1)$ & $(1)$ & \\
\hline \multicolumn{9}{|l|}{ Level of education } \\
\hline Certificate & $78(52.7)$ & $112(50.7)$ & 0.145 & 0.703 & $164(51.2)$ & $36(50)$ & 0.037 & 0.848 \\
\hline Diploma & $70(47.3)$ & $109(49.3)$ & (1) & & $156(48.8)$ & $36(50)$ & (1) & \\
\hline \multicolumn{9}{|l|}{ Basic salary (RM) } \\
\hline $1,000-2,000$ & $121(81.8)$ & $189(85.5)$ & 3.470 & 0.176 & $261(81.6)$ & $56(77.8)$ & 0.814 & 0.666 \\
\hline $2,001-3,000$ & $25(16.9)$ & $32(14.5)$ & (2) & & $54(16.9)$ & $14(19.4)$ & (2) & \\
\hline$>3000$ & $2(1.4)$ & $0(0)$ & & & $5(1.6)$ & $2(2.8)$ & & \\
\hline \multicolumn{9}{|l|}{ Assembly Unit } \\
\hline Paint shop & $40(27.0)$ & $69(31.2)$ & 1.026 & 0.599 & $103(32.2)$ & $23(31.9)$ & 0.343 & 0.842 \\
\hline Body shop & $59(39.9)$ & $88(39.8)$ & (2) & & $114(35.6)$ & $28(38.9)$ & (2) & \\
\hline Assembly shop & $49(33.1)$ & $64(29.0)$ & & & $103(32.2)$ & $21(29.2)$ & & \\
\hline
\end{tabular}

Table 3. Difference in mean scores (SD) of DASS-21 Stress subscale within and between groups across time

\begin{tabular}{lcccc}
\hline & $\begin{array}{c}\text { Baseline } \\
\text { Mean }\end{array}$ & $\begin{array}{c}9^{\text {th }} \text { month } \\
\text { Mean }\end{array}$ & $\begin{array}{c}p \text {-value } \\
\text { (within group) }\end{array}$ & Effect size \\
& (SD) & (SD) & & \\
\hline Group A & 34.57 & 26.10 & $<0.001^{*}$ & 0.6 (moderate) \\
& $(3.74)$ & $(6.64)$ & & \\
Group B & 34.83 & 32.62 & $<0.001^{*}$ & 0.2 (small) \\
& $(2.40)$ & $(4.83)$ & & \\
$p$-value (between groups) & 0.29 & $<0.001^{*}$ & & \\
Effect size & 0.1 (small) & 1.2 (large) & & \\
\hline
\end{tabular}

*statistical significance at $\alpha=0.05$

ing that when the two groups were combined, the average at Baseline (Mean=34.70) was higher than the average at $9^{\text {th }}$ month $($ Mean $=29.36)$. Additionally, the interaction between group and time was also statistically significant $[F(1,759)=272.45, p<0.001]$, indicating there was a significant difference in the Mean Stress subscale scores between Baseline and $9^{\text {th }}$ month for the two groups.

\section{Outcomes of DASS-21 Depression subscale}

Table 5 shows the change in Mean score of DASS-21 Depression subscale for Group A and B from Baseline to $9^{\text {th }}$ month (within group). Reduction in Mean DASS-21 Depression scores occurred in Group A and Group B across
Table 4. Results of Repeated Measure ANOVA with DASS-21 Stress subscale as the dependent variable across time

\begin{tabular}{lrrrrr}
\hline $\begin{array}{c}\text { Source of } \\
\text { variance }\end{array}$ & \multicolumn{1}{c}{$\begin{array}{c}\text { Sum of } \\
\text { squares }\end{array}$} & df & \multicolumn{1}{c}{$\begin{array}{c}\text { Mean } \\
\text { squares }\end{array}$} & F & $p$ value \\
\hline Group & $7,139.87$ & 1 & $7,139.87$ & 270.27 & $<0.001^{*}$ \\
Error (group) & $20,054.89$ & 759 & 26.42 & & \\
Time & $3,687,695.25$ & 1 & $3,687,695.25$ & $48,335.71$ & $<0.001^{*}$ \\
Group*time & $20,786.04$ & 1 & $20,786.04$ & 272.45 & $<0.001^{*}$ \\
Error (time) & $57,906.68$ & 759 & 76.30 & & \\
\hline
\end{tabular}

*statistical significance at $\alpha=0.05$

time $(p<0.001)$ with a small effect size $(0.2)$. Table 5 also shows the difference in Mean score of DASS-21 Depression subscale between the groups at Baseline and $9^{\text {th }}$ month. 
Table 5. Difference in Mean scores (SD) of DASS-21 Depression subscale within and between groups across time

\begin{tabular}{lcccc}
\hline & $\begin{array}{c}\text { Baseline Mean } \\
(\mathrm{SD})\end{array}$ & $\begin{array}{c}9^{\text {th }} \text { month Mean } \\
(\mathrm{SD})\end{array}$ & $\begin{array}{c}p \text {-value } \\
\text { (within group) }\end{array}$ & Effect size \\
\hline Group A & 0.53 & 0.03 & $<0.001^{*}$ & 0.2 (small) \\
& $(0.98)$ & $(0.26)$ & & \\
Group B & 0.47 & 0.03 & $<0.001^{*}$ & 0.2 (small) \\
& $(0.94)$ & $(0.26)$ & & \\
$p$-value (between groups) & 0.14 & 1.0 & & \\
Effect size & $<0.1$ (very small) & $<0.1$ (very small) & & \\
\hline
\end{tabular}

*statistical significance at $\alpha=0.05$

Table 6. Results of Repeated Measure ANOVA with DASS-21 Depression subscale as the dependent variable across time

\begin{tabular}{lrrrrc}
\hline $\begin{array}{c}\text { Source of } \\
\text { variance }\end{array}$ & $\begin{array}{c}\text { Sum of } \\
\text { squares }\end{array}$ & df & $\begin{array}{c}\text { Mean } \\
\text { squares }\end{array}$ & F & $p$ value \\
\hline Group & 0.31 & 1 & 0.31 & 0.71 & $0.4(>0.05)$ \\
Error (group) & 334.54 & 759 & 0.44 & & \\
Time & 103.00 & 1 & 103.00 & 186.06 & $<0.001^{*}$ \\
Group*time & 0.31 & 1 & 0.31 & 0.57 & $0.4(>0.05)$ \\
Error (time) & 420.160 & 759 & 0.55 & & \\
\hline
\end{tabular}

*statistical significance at $\alpha=0.05$

Table 7. Difference in Mean scores (SD) of DASS-21 Anxiety subscale within and between groups across time

\begin{tabular}{lcccc}
\hline & $\begin{array}{c}\text { Baseline Mean } \\
(\mathrm{SD})\end{array}$ & $\begin{array}{c}9^{\text {th }} \text { month Mean } \\
(\mathrm{SD})\end{array}$ & $\begin{array}{c}p \text {-value } \\
\text { (within group) }\end{array}$ & Effect size \\
\hline Group A & 0.04 & 0.01 & 0.052 & $<0.1$ (very small) \\
& $(0.27)$ & $(6.64)$ & & \\
Group B & 0.05 & 0.01 & 0.025 & $<0.1$ (very small) \\
& $(0.31)$ & $(0.16)$ & & \\
$p$-value (between groups) & 0.66 & 0.70 & & \\
Effect size & $<0.1$ (very small) & $<0.1$ (very small) & & \\
\hline
\end{tabular}

* statistical significance at $\alpha=0.05$

However, there were no significant differences (very small effect size $<0.1)$ in the mean scores of DASS-21 Depression subscale at baseline and at $9^{\text {th }}$ month, between Group A and B. In summary, the PMR therapy in Group A as well as pamphlets in Group B caused a small reduction in Depression levels among automotive assembly line workers over time.

Table 6 shows there was no significant main effect for group assignment $[\mathrm{F}(1,759)=0.71, p>0.05]$, indicating that both groups did not differ in their average DASS-21 Depression subscale scores across time. However there was a significant main effect for time $[\mathrm{F}(1,759)=186.06$, $p<0.001]$, indicating that when the two groups were combined, the average at Baseline (Mean $=0.50)$ was slightly higher than the average at $9^{\text {th }}$ month $($ Mean $=0.03)$. How- ever, the interaction between group and time was not statistically significant $[\mathrm{F}(1,759)=0.57, p>0.05]$, indicating there was no significant difference in the Mean Depression subscale scores between Baseline and $9^{\text {th }}$ month for the two groups.

\section{Outcomes of DASS-21 Anxiety subscale}

Table 7 shows the change in mean score of DASS-21 Anxiety subscale for Group A and B from Baseline to $9^{\text {th }}$ month (within group). No significant changes occurred in Group A and Group B with very small effect sizes $(<0.1)$ across time. Table 7 also shows the difference in mean score of DASS-21 Anxiety subscale between the groups at Baseline and $9^{\text {th }}$ month. There were no significant differences with very small effect sizes $(<0.1)$ in the mean 
Table 8. Results of Repeated Measure ANOVA with DASS-21 Anxiety subscale as the dependent variable across time

\begin{tabular}{lrrccc}
\hline $\begin{array}{c}\text { Source of } \\
\text { variance }\end{array}$ & $\begin{array}{c}\text { Sum of } \\
\text { squares }\end{array}$ & df & $\begin{array}{c}\text { Mean } \\
\text { squares }\end{array}$ & F & $p$ value \\
\hline Group & 0.002 & 1 & 0.002 & 0.03 & $0.85(>0.05)$ \\
Error (group) & 35.64 & 759 & 0.05 & & \\
Time & 1.06 & 1 & 1.06 & 15.79 & $<0.001^{*}$ \\
Group*time & 0.02 & 1 & 0.02 & 0.28 & $0.60(>0.05)$ \\
Error (time) & 50.93 & 759 & 0.07 & & \\
\hline
\end{tabular}

*statistical significance at $\alpha=0.05$

score of DASS-21 Anxiety subscale at baseline and at $9^{\text {th }}$ month between Group A and B, indicating that the PMR therapy in Group A and pamphlets in Group B did not play a significant role in the reduction of Anxiety levels among automotive assembly line workers over time.

Table 8 shows there was no significant main effect for group assignment $[\mathrm{F}(1,759)=0.03, p>0.05]$, indicating that both groups did not differ in their average DASS-21 Anxiety subscale scores across time. There was a significant main effect for time $[\mathrm{F}(1,759)=15.79, p<0.001]$, indicating that when the two groups were combined, the average at Baseline was slightly higher $(0.05)$ than the average at $9^{\text {th }}$ month (0.01) in both groups. However, the interaction between group and time was not statistically significant $[\mathrm{F}(1,759)=0.28, p>0.05]$, indicating there was no significant difference in the mean Anxiety subscale scores between Baseline and $9^{\text {th }}$ month for the two groups.

\section{Discussion}

At the end of study, there were 148 respondents in Plant A and 221 respondents in Plant B. Response rate was 32\% in Plant A whilst Plant B reported $75 \%$ response rate among the participants. Non participants or drop outs accounted for $68 \%$ in Plant A as compared to $25 \%$ in Plant B. Those whom dropped out of the study mainly reported 'poor work schedules' as in lack of time to come for the relaxation therapy on a regular 2 monthly interval basis. Other reasons cited were 'forgot to come' and 'personal reasons'. Statistically significant results were obtained even though the attrition rate was high in the PMR group as compared to the pamphlet group. Active relaxation techniques like PMR require a higher level of motivation for the participants to be compliant for effectiveness of the treatment to be demonstrated ${ }^{34)}$. A large sample size was used, reporting a moderate effect size in the trial group (0.6) and accepted treatment lengths ( 5 sessions over 9 months) for the effectiveness of the stress management training ${ }^{35)}$.
The format of this study involved a simple model without multiple measurement scales or multiple treatments. This allowed for careful attention to detail and control. Despite the two groups being well balanced with homogeneity in the demographic variables, there were some differences in terms of work demands and index of production between the two plants. Both the plants had a 12 hour, two shift system with Shift 1 commencing from 7 am to $7 \mathrm{pm}$ whereas Shift 2 was from $7 \mathrm{pm}$ to $7 \mathrm{am}$. However, Plant A produced an average of 250,000 units of passenger vehicles whilst Plant B produced an average of 100,000 units of passenger vehicles per annum. Plant A had inevitably a higher intensity of physical work load and demands to meet production targets as compared to Plant B. With this in view, Plant A was more ideal to examine the effectiveness of the PMR techniques considering it had a bigger study population with higher job demands. Plant B as a control group accounted for the effect of experience and learning among the participants. Future studies should acknowledge this limitation and perhaps a detailed analysis conducted to correlate the workload differences and index of production of the factories to self-perceived stress, depression and anxiety levels among the workers.

The present study suggests that even $10-15$ minutes of PMR therapy per session was able to decrease self-perceived stress levels at the workplace. Our primary research question on whether PMR had a specific effect on work stress was best assessed post-intervention, with 5 followup assessments. This strategy allowed us to assess whether the respondents continued using the intervention and the degree to which the benefits were maintained. Our study further improved a recent meta-analysis ${ }^{36)}$ suggesting that at least 6 sessions were needed to achieve favourable effects on health outcomes, otherwise the favourable effects were limited to just knowledge and professional efficacy.

The use of DASS-21 in our study may be considered not adequately objective, but it should be noted that the use of such measures is both a reliable and standard approach to studying the effects of interventions for work stress. There is good evidence that these measures are clinically useful and reliable. Although more objective measures might be more desirable in studies like this, there is currently no agreement amongst work stress researchers about which objective measures are both reliable and feasible for use in field studies ${ }^{37)}$.

Only one study has tested the effects of a short duration, easy-to-implement stress management training to reduce stress in the automotive industry in Malaysia but with a multi component entity ${ }^{5)}$. Our study is the first in-depth, 
single component study on effects of individual-focused PMR therapy on stress in the automotive industry. Studies that examine the effects of short duration, individualfocused stress management training as part of WHPP are deeply lacking. Poor organizational support that presume, stress management training is time-consuming, expensive and inability of workers to practice coping skills also attribute to high stress at the workplace ${ }^{38)}$.

This study has a number of strengths that assert progress in the field of PMR therapy as part of WHPP to alleviate job stress. In the intention-to-treat analysis, a favourable significant intervention effect was observed in the PMR group as compared to the pamphlet group. The findings are in concordance to a meta-analysis that reported individualfocused stress management interventions are effective in reducing workers' stress-related issue ${ }^{36,38)}$. Per-protocol analysis conducted had the advantage to provide a new treatment to show additional efficacy and it most closely reflects the scientific model underlined in the protocol.

Stress management and exercise related techniques are found to significantly reduce the long term side effects of stress. Other benefits include enhanced efficiency, effectiveness, increase in morale and overall attitude at the workplace $^{39-45)}$. The format employed in the study involved a simple model without multiple measurement scales or multiple treatments.

This allowed for careful attention to detail and control. In addition, the use of a comparison group accounted for the effect of learning experience among the participants. The two groups were well balanced at baseline. Preference for social contact afforded by direct, face-to-face individual-focused relaxation therapy sessions at the worksite reinforced effectiveness and somewhat the curiosity of the interested assembly line workers to participate ${ }^{46-52)}$.

Limitations were that assessment with self-administered questionnaires was performed immediately after the course and long term durable outcomes were not assessed. By increasing the retention of teaching outcomes, continuous application and integrated repetition is mandatory, which was not attainable merely by the short duration interventions in the current study. Further studies using rigorous study designs as well as valid and objective evaluation instruments, such as salivary cortisol levels ${ }^{53)}$ should be considered to evaluate the effects of individual-focused PMR techniques. The present study could not provide data on how long the effects remained after the intervention program. The post treatment measures were taken immediately after training. It would be beneficial to know how long these effects lasted and the cumulative effects of the intervention program. Another limitation of this study is that all of the study data were self-reported, which may have introduced bias. However, self-report is often the only feasible strategy to gather information concerning workers' working conditions ${ }^{54)}$.

The five reinforcement sessions in Group A itself might have served as treatment bias. Participants in Group A would have acquired the necessary skills and knowledge more effectively over the five reinforcement sessions which would have favoured a desired intervention effect as compared to Group B with only 2 reinforcement sessions. The study design was neither blinded nor randomised which might have introduced bias to the outcomes reported by participants and a confounding bias due to unknown confounders.

The participants were all male workers from the assembly plant which may not be applicable to the general working population. The frequency and duration of practice of PMR techniques before each reinforcement sessions were not available because the participants did not keep a detailed record despite being informed. The extent of practice at home and the workplace could have been analysed further which may have had some influence on the intervention effects.

\section{Conclusion}

This study contributes to the advancing knowledge in mental health among automotive assembly line workers and minimizing knowledge gaps in literature, learned resourcefulness and health. Results indicated that PMR therapy is effective in reducing some aspects of self-perceived occupational stress in these workers. Given the high stress levels reported among automotive assembly workers in previous studies including those in Malaysia ${ }^{3,5,6)}$ short duration WHPP may facilitate automotive workers to be more productive and effective in service delivery ${ }^{46)}$.

As preventive interventional studies targeting healthy workers also remain rather scarce in Malaysia, further research in this field is necessary, including examination of the frequency and methods of intervention sessions, the effects of intervention by gender, a larger and more varied sample and prospective study designs with more objective measures like job exposure matrix ${ }^{55)}$.

\section{Ethics}

Ethical issues (Including plagiarism, Informed Consent, misconduct, data fabrication and/or falsification, double 
publication and/or submission and redundancy) have been completely observed by the authors. The study protocol was reviewed and approved by the Research and Ethics Committee of University Malaya on 16th of January 2012 (MEC Reference Number: 895.11).

\section{Acknowledgements}

We would like to thank all the respondents, plant supervisors and managers of both automotive assembly plants who assisted in the study.

\section{References}

1) Leka S, Griffiths A, Cox T (2004) Work organization and stress. Nottingham: UK. World Health Organization.

2) Ugoji EI, Isele G (2009) Stress management \& corporate governance in Nigerian organizations. European Journal of Scientific Research 27, 472-8.

3) Oleske DM, Neelakantan J, Andersson GB, Hinrichs BG, Lavender SA, Morrissey MJ, Zold-Kilbourn P, Taylor E (2004) Factors affecting recovery from work-related, low back disorders in autoworkers. Arch Phys Med Rehabil 85, 1362-4.

4) KvarnstrÖm S (1997) Stress prevention for blue-collar workers in assembly-line production. Geneva: International Labour Office (ILO): 1-32.

5) Edimansyah B, Rusli B, Naing L (2008) Effects of short duration stress management training on self-perceived depression, anxiety and stress in male automotive assembly workers: a quasi-experimental study. J Occup Med Toxicol $3,28$.

6) Lottridge D (2004) Work at the Uddevalla Volvo Plant from the perspective of the demand control model. Bull Sci Technol Soc 24, 435-40.

7) Karasek R, Baker D, Marxer F, Ahlbom A, Theorell T (1981) Job decision latitude, job demands, and cardiovascular disease: a prospective study of Swedish men. Am J Public Health 71, 694-705.

8) Mutum DS (2000) Overview of the Malaysia Automotive Industry, Retrieved from the World Wide Web: http://www. ah-ok.com/auto/overview.html

9) Cox T, Griffiths A, Rial-González E (2000) Research on Work-Related Stress. European Agency for Safety \& Health at Work. Belgium, Luxembourg: Office for Official Publications of the European Communities.

10) Fairbrother K, Warn J (2003) Workplace dimensions, stress and job satisfaction. J Manag Psychol 18, 8-21 (doi:10.110 8/02683940310459565).

11) Lamontagne $\mathrm{AD}$, Keegel $\mathrm{T}$, Louie AM, Ostry A, Landsbergis PA (2007) A systematic review of the job-stress intervention evaluation literature, 1990-2005. Int J Occup Environ Health 13, 268-80.
12) Bunce $D$ (1997) What factors are associated with the outcome of individual-focused worksite stress management interventions? J Occup Organ Psychol 70, 1-17.

13) Jones DL, Tanigawa T, Weiss SM (2003) Stress management and workplace disability in the US, Europe and Japan. J Occup Health 45, 1-7.

14) Kawaharada M, Ueda I, Yoshioka E, Hirano M, Ikeno T, Shindou Y, Kishi R (2009) Depression prevention program for workers in private companies: A randomized controlled trial. Open J Nurs 2013, 114-21.

15) Ganster DC, Murphy LR (2000) Workplace interventions to prevent stress-related illnesses: Lessons from research and practice. In: Cooper CL, Lock EA, eds. Industrial and Organizational Psychology, Oxford: Blackwell; p. 34-51.

16) Umanodan $R$, Kobayashi $Y$, Nakamura $M$, KitaokaHigashiguchi K, Kawakami N, Shimazu A (2009) Effects of a worksite stress management training program with six short-hour sessions: a controlled trial among Japanese employees. J Occup Health 51, 294-302.

17) Barlow DH (2007) Principles and practice of stress management. P. M. Lehrer, R. L. Woolfolk, \& W. E. Sime (Eds.) Guilford Press.

18) Payne RA (2000) Relaxation Techniques: A Practical Handbook for the Health Care Professional (2nd ed.) London: Harcourt Publishers Limited.

19) Jacobson E (1938) Progressive relaxation (2nd ed.) Chicago: University of Chicago Press.

20) Sadock BJ, Sadock VA (2003) Psychotherapies. In Benjamin James Sadock and Virginia A. Sadock (Eds.), Synopsis of Psychiatry Behavioural Sciences Clinical Psychiatry. Philadelphia: Lippincott Williams and Wilkins.

21) Ghoncheh S, Smith JC (2004) Progressive muscle relaxation, yoga stretching, and $\mathrm{ABC}$ relaxation theory. J Clin Psychol 60, 131-6.

22) Altman DG, Gore SM, Gardner MJ, Pocock SJ (1983) Statistical guidelines for contributors to medical journals. $\mathrm{Br}$ Med J (Clin Res Ed) 286, 1489-93.

23) Julious SA (2004) Sample sizes for clinical trials with normal data. Stat Med 23, 1921-86.

24) Isa MR, Moy FM, Abdul Razack AH, Zainuddin ZM, Zainal NZ (2013) Impact of applied progressive deep muscle relaxation training on the level of depression, anxiety and stress among prostate cancer patients: a quasi-experimental study. Asian Pac J Cancer Prev 14, 2237-42.

25) Lovibond SH, Lovibond PF (2002) Manual for the Depression Anxiety Stress Scales 2nd edition. Sydney: School of Psychology, University of New South Wales. 18.

26) Edimansyah BA, Rusli BN, Naing L, Mazlan BA, Rampal KG, Shamsul Bahri BMT, Nik Khairol Reza BMY, Ahmad Syaarani BY, Azwan BA, Mazalisah BM, Kamarudin BH (2005) Reliability and concurrent validity of the Malay version of Depression Anxiety Stress Scale (DASS) in automotive assembly workers in Malaysia, Malaysian. J Public Health Med 5, 58.

27) Lovibond PF, Lovibond SH (1995) Manual for the Depres- 
sion Anxiety Stress Scales (2nd ed.) Sydney: Psychology Foundation of Australia.

28) Bados A, Solanas A, Andrés R (2005) Psychometric properties of the Spanish version of Depression, Anxiety and Stress Scales (DASS). Psicothema 17, 679-83.

29) Apóstolo JLA, Mendes AC, Azeredo ZA (2006) Adaptation to Portuguese of the Depression, Anxiety and Stress Scales (DASS). Rev Lat Am Enfermagem 14, 863-71.

30) Akin A, Çetin B (2007) The Depression Anxiety and Stress Scale (DASS): The study of validity and reliability. Educ Sci Theor Pract 7, 260-8.

31) Musa R, Fadzil MA, Zain Z (2007) Translation, validation and psychometric properties of Bahasa Malaysia version of the Depression Anxiety and Stress Scales (DASS). Asian J Psychiatr 8, 82-9.

32) Cohen J (1992) A power primer. Psychol Bull 112, 155-9.

33) Schulz KF, Altman DG, Moher D; CONSORT Group (2010) CONSORT 2010 statement: updated guidelines for reporting parallel group randomised trials. BMJ 340, c332 (doi:10.1136/bmj.c332).

34) Avants SK, Margolin A, Salovey P (1990) Stress management techniques: Anxiety reduction, appeal, and individual differences. Imagin Cogn Pers 10, 3-23.

35) Linden W (1990) Autogenic training. New York: Guilford.

36) van der Klink JJL, Blonk RWB, Schene AH, van Dijk FJH (2001) The benefits of interventions for work-related stress. Am J Public Health 91, 270-6.

37) Richardson KM, Rothstein HR (2008) Effects of occupational stress management intervention programs: a metaanalysis. J Occup Health Psychol 13, 69-93.

38) Yung PM, Fung MY, Chan TM, Lau BW (2004) Relaxation training methods for nurse managers in Hong Kong: a controlled study. Int J Ment Health Nurs 13, 255-61.

39) Varvogli L, Darviri C (2011) Stress Management Techniques. Evidence-based procedures that reduce stress and promote health. Health Sci J 5.

40) Heaney CA, Israel BA, House JS (1994) Chronic job insecurity among automobile workers: effects on job satisfaction and health. Soc Sci Med 38, 1431-7.

41) Plaisier I, de Bruijn JG, de Graaf R, ten Have M, Beekman AT, Penninx BW (2007) The contribution of working conditions and social support to the onset of depressive and anxiety disorders among male and female employees. Soc Sci Med 64, 401-10.

42) Rugulies R, Bültmann U, Aust B, Burr H (2006) Psychosocial work environment and incidence of severe depressive symptoms: prospective findings from a 5-year follow-up of the Danish work environment cohort study. Am J Epidemiol 163, 877-87.

43) Stansfeld SA, Fuhrer R, Shipley MJ, Marmot MG (1999) Work characteristics predict psychiatric disorder: prospective results from the Whitehall II Study. Occup Environ Med
56, 302-7.

44) Niedhammer I, Goldberg M, Leclerc A, Bugel I, David S (1998) Psychosocial factors at work and subsequent depressive symptoms in the Gazel cohort. Scand J Work Environ Health 24, 197-205.

45) Ferrie JE, Shipley MJ, Stansfeld SA, Marmot MG (2002) Effects of chronic job insecurity and change in job security on self reported health, minor psychiatric morbidity, physiological measures, and health related behaviours in British civil servants: the Whitehall II study. J Epidemiol Community Health 56, 450-4.

46) Blumenthal JA, Sherwood A, Babyak MA, Watkins LL, Waugh R, Georgiades A, Bacon SL, Hayano J, Coleman RE, Hinderliter A (2005) Effects of exercise and stress management training on markers of cardiovascular risk in patients with ischemic heart disease: a randomized controlled trial. JAMA 293, 1626-34.

47) Bhui K, Dinos S, Stansfeld S, White P (2012) A Synthesis of the Evidence for Managing Stress at Work: A Review of the Reviews Reporting on Anxiety, Depression, and Absenteeism. Journal of Environmental and Public Health 2012:21 pages.

48) Majumdar M, Grossman P, Dietz-Waschkowski B, Kersig S, Walach H (2002) Does mindfulness meditation contribute to health? Outcome evaluation of a German sample. J Altern Complement Med 8, 719-30, discussion 731-5.

49) Napoli M (2004) Mindfulness training for teachers: A pilot program. Complement Health Pract Rev 9, 31-42.

50) Reynolds S, Shapiro DA (1991) Stress reduction in transition: Conceptual problems in the design, implementation and evaluation of worksite stress management intervention. Hum Relat 44, 717-33.

51) Shimazu A, Okada Y, Sakamoto M, Miura M (2003) Effects of stress management program for teachers in Japan: a pilot study. J Occup Health 45, 202-8.

52) Woo HJ, Park KS (2002) The effect of muscle relaxation therapy on mood state and job stress of clinical nurses. Journal of Korean Academy Adult Nursing 14, 44-52.

53) Yu SF, Jiang KY, Zhou WH, Wang S (2008) Relationship between occupational stress and salivary SIgA and lysozyme in assembly line workers. Chin Med J (Engl) 121, 1741-3 [English Edition].

54) Karasek R, Brisson C, Kawakami N, Houtman I, Bongers P, Amick B (1998) The Job Content Questionnaire (JCQ): an instrument for internationally comparative assessments of psychosocial job characteristics. J Occup Health Psychol 3, 322-55.

55) Sieber WK Jr, Sundin DS, Frazier TM, Robinson CF (1991) Development, use, and availability of a job exposure matrix based on national occupational hazard survey data. Am J Ind Med 20, 163-74. 